\title{
Importância dos laboratórios de análises clínicas no cenário da pandemia do novo Coronavírus
}

\section{ARTIGO DE REVISÃo}

MARCELINO NETO, Antonio ${ }^{1}$, FREIRE, Lorena Lacerda ${ }^{2}$

MARCELINO NETO, Antonio. FREIRE, Lorena Lacerda. Importância dos laboratórios de análises clínicas no cenário da pandemia do novo Coronavírus. Revista Científica Multidisciplinar Núcleo do Conhecimento. Ano 05, Ed. 10, Vol. 24, pp. 51-60. Outubro de 2020. ISSN: 2448-0959, Link de acesso:

\section{RESUMO}

Em 11 de março de 2020 a COVID-19 foi declarada como pandemia. Essa doença causada pelo novo coronavírus assolou todo o planeta de uma maneira jamais vista. Este trabalho tem como objetivo demonstrar a importância dos laboratórios de análises clínicas no cenário da pandemia do novo coronavírus, além disso também busca descrever os principais métodos utilizados por esses profissionais de saúde que trabalham com análises clínicas e demonstrar a contribuição dos laboratórios no enfrentamento da pandemia e na retomada do convívio social. Frente ao cenário atual da pandemia esse estudo de revisão foi realizado em artigos publicados nas bases de dados: Google Acadêmico, SciELO e PUBMED, fazendo uso dos descritores: análises clínicas, laboratório, coronavírus e pandemia. Depois da análise dos artigos selecionados, conclui-se que os laboratórios desempenham uma função crucial no combate ao novo coronavírus, enfrentam os riscos de contaminação, concomitantemente à falta de recursos no atendimento da demanda de testagem,

\footnotetext{
${ }^{1}$ Pós-graduando em Análises Clinicas e Microbiologia, Pós-Graduando em Ensino de Biologia e Química, Graduação em Ciências Biológicas.

2 Pós-graduação em Fisioterapia Pélvica - Uroginecologia Funcional, Graduação em Fisioterapia.
} 
acompanhamento adequado dos diagnósticos e produção de resultados dos testes no enfrentamento à pandemia.

Palavras-chave: Análises clínicas, laboratório, coronavírus, pandemia.

\section{INTRODUÇÃO}

A Organização Mundial da Saúde (OMS) classificou em 30 de janeiro de 2020 a doença causada pelo novo coronavírus (COVID-19) ou SARS-CoV-2 (severe acute respiratory syndrome coronavirus 2), como o mais alto nível de alerta mundial, declarando-a Emergência de Saúde Pública de Importância Internacional. Essa patologia surgiu na província de Wuhan em novembro 2019, e em aproximadamente cinco meses, classificou-se como pandemia.

Até o mês de maio o ministério da saúde distribuiu 6,9 milhões de testes para detecção do coronavírus com a intenção de aplicação um grande percentual da população Brasileira, por meio de uma estratégia chamada "Diagnosticar para cuidar", com 2,1 milhões de testes RT-PCR e 4,7 milhões testes rápidos. Para realização das testagens são necessários profissionais qualificados na correta avaliação e interpretação dos resultados. Sendo os testes moleculares laboratoriais, o padrão referência para o diagnóstico de COVID-19.

A pandemia colocou em evidência a importância de vários profissionais que trabalham na área da saúde. Dentre estes, os que atuam nos laboratórios e nas análises clínicas de função indispensável neste contexto, atuando na coleta dos materiais biológicos, no diagnóstico inicial, acompanhamento dos pacientes mais graves e na análise bioquímica de amostras sorológicas.

Nos dias atuais, a corrida pela realização de testes para detecção do vírus e nas pesquisas para desenvolvimento de uma vacina eficaz no combate desse patógeno, gera uma sobrecarga nos profissionais que atuam nos laboratórios de análises clínicas, abrangendo farmacêuticos, bioquímicos, biólogos, médicos ou biomédicos, desde que, tenham uma preparação nessa área de atuação. 
Presume-se que haja necessidade de uma maior atenção à importância da atuação dos profissionais de Saúde no âmbito da realização dos testes laboratoriais. Desta forma, os especialistas em análises clínicas e os laboratórios são essenciais na saúde pública, atuando juntamente com uma equipe multidisciplinar, estão presentes no diagnóstico e acompanhamento dos pacientes infectados pela COVID-19.

O presente trabalho tem por objetivo principal demonstrar a importância dos laboratórios de análises clínicas no cenário da pandemia do novo coronavírus, além disso também busca descrever os principais métodos utilizados por esses profissionais de saúde que trabalham com análises clínicas e demonstrar a contribuição dos laboratórios no enfrentamento da pandemia e na retomada do convívio social.

Este estudo está pautado nas relevantes atuações que os laboratórios desempenham na saúde pública, desde antes da pandemia, as quais acentuaram-se durante essa crise mundial. Foram evidenciadas as fragilidades encontradas no enfrentamento da COVID-19, presentes no controle das pesquisas e testagens pelos serviços laboratoriais. Nesse sentido, torna-se relevante a investigação sobre os manejos adequados quanto à realização dos testes de identificação desta doença.

Trata-se de um estudo de revisão de literatura do tipo integrativa, onde foram utilizados artigos científicos disponíveis nas seguintes bases de dados: Google acadêmico, Scientific Electronic Library Online (SciELO) e PUBMED, tendo os seguintes critérios de inclusão: artigos publicados no período de 2019 a 2020, e que são pertinentes ao tema da pesquisa. Os critérios de exclusão foram: Artigos fora do tema, artigos duplicados e que não estão no período de tempo estipulado. Considerando os seguintes Descritores em Ciências da Saúde (DeCS): Análises Clínicas, Laboratório, COVID-19 e Pandemia. No total foram encontrados 559 artigos na base de dados do Google Acadêmico; SciELO: 11 e PUBMED: 4; de acordo com os critérios para a exclusão foram selecionados 23 , após a leitura e avaliação minuciosa restaram 13 estudos.

\section{DESENVOLVIMENTO}




\subsection{LABORATÓRIO DE ANÁLISES CLÍNICAS NA PANDEMIA DO NOVO CORONAVÍRUS}

De acordo com as ideias de Oliveira (2020) que elucida sobre as contribuição dos laboratórios de análises clínicas na pandemia destaca que a COVID-19 pôs em evidência o papel central que as análises clínicas desempenham na prestação de cuidados na saúde, intervindo no diagnóstico inicial da infecção viral, observações que foram feitas em Portugal mas que se aplicam perfeitamente a situação do Brasil e ainda ressalta a participação desses profissionais em outros momentos além da testagem como a monitorização sorológica das populações afetadas, no acompanhamento e análise bioquímica de amostras dos doentes hospitalizados com formas mais graves da doença e nos inquéritos sorológicos.

Em um cenário de crise Mundial causada pelo novo coronavírus onde se tem necessidade de informações atualizadas, Lippi e Plebani (2020), nos falam da medicina laboratorial que mais uma vez se destaca, desempenhando um papel base no enfrentamento da pandemia. Todos os profissionais que trabalham nos laboratórios clínicos devem ser valorizados e parabenizados, independentemente de sua função ou formação, por fornecerem um apoio eficiente ainda que haja equipamentos reduzidos; esses profissionais estão fornecendo de forma contínua resultados vitais dos testes para diagnosticar, direcionar prognósticos e facilitar o gerenciamento dos pacientes com COVID-19.

Em todas as mídias são perceptíveis as necessidades de um grande número de testagens para os casos confirmados de COVID-19, mas pouco se fala nos profissionais que atuam na realização e elaboração dos resultados dos testes. Oliveira (2020) evidencia que os testes necessitam de ser convenientemente executados, avaliados e interpretados de modo à direcionarem as decisões clínicas adequadas e ajudar às decisões políticas futuras, no tange ao respeito do desconfinamento na sociedade. Ressaltando a necessidade de profissionais capacitados para atuação dos laboratórios. 
Vieira; Emery e Andriolo (2020) destacam que o número de testes laboratoriais e equipamentos disponíveis no país não são suficientes para atender a demanda atual, além de ser essa uma metodologia que necessita tempo e trabalho já que a extração e realização dos testes são manuais, gerando assim o acúmulo de exames pendentes, principalmente, mas não exclusivamente, na rede pública dos Laboratórios Centrais de Saúde Pública (LACENs). O que remete a necessidade de um maior investimento no desenvolvimento de pesquisas, capacitação de profissionais e equipamentos para aumentar a capacidade dos laboratórios já existentes e com gerenciamento dos novos laboratórios.

Segundo Xavier et al. (2020) a análise laboratorial tem um papel fundamental na definição do diagnóstico, coleta e processamento de material biológico, na avaliação do acompanhamento do caso e na previsão do prognóstico dos pacientes com COVID-19, este se torna indispensável para um sistema de saúde eficiente no cenário pandêmico. Além disso, é importante salientar que as investigações laboratoriais são a base dos estudos epidemiológicos, orientam as estratégias governamentais mais eficazes relacionadas com a saúde, ou seja, esses dados são essenciais na formulação das políticas públicas para a resolução desta crise de saúde, auxiliam na retomada das atividades econômicas e fornecem subsídios para as decisões médicas baseadas em evidências.

Refletindo sobre as palavras de Magalhães (2020) em relação às diretrizes para a realização dos testes para COVID-19, podemos concluir que como em todas as outras áreas do diagnóstico laboratorial, devem ser sempre utilizados controles internos, de biossegurança para assegurar a qualidade do produto biológico, a segurança dos profissionais, o processo de diagnóstico laboratorial. A coleta correta das amostras e a fase da infecção são fatores determinantes para a detecção laboratorial, um erro nesses fatores pode comprometer os resultados significativos.

Ressaltando a evolução na qualidade dos métodos laboratoriais mais recentes na detecção do novo coronavírus, Loeffelholz e Tang (2020) afirmam que com as novas pesquisas, houve um avanço considerável das metodologias de testagem tornando as mais rápidas e com maior eficácia, altamente sensíveis e específicos, estão 
gradualmente substituindo os padrões ouro convencionais. Percebe-se a efetividade das pesquisas e nota-se o esforço dos profissionais que trabalham nos laboratórios e das equipes de saúde, buscando também facilitar a execução e a interpretação dos resultados para um diagnóstico rápido e eficaz.

Nesse período crítico para a saúde pública Lippi e Plebani (2020) refletem a necessidade algumas estratégias proativas e reativas que poderiam ser identificadas para enfrentar este sério desafio, com um momento de redução nas verbas destinadas à pesquisa. Para superar essas dificuldades são imprescindíveis grandes investimentos em recursos laboratoriais convencionais, reforço de redes regionais de laboratórios clínicos, instalação de laboratórios móveis, além de ser proativo no estabelecimento de planos de emergência laboratoriais.

\subsection{TESTES LABORATORIAIS PARA DETECTAR A COVID-19}

Para se falar em testagem laboratorial, primeiro é necessário entender sua importância. Silva; Silva ; Guarines et al. (2020) respaldam sobre o aspecto clínico, afirmando sobre o diagnóstico dessa doença que infectou a humanidade de forma rápida; causada pelo novo coronavírus, apresenta dificuldades devido às semelhantes "queixas" provocadas por outros patógenos respiratórios, incluindo os vírus influenza e parainfluenza. Portanto, o diagnóstico laboratorial é crucial para o manejo clínico dos pacientes e a implementação de estratégias de controle da doença para um enfrentamento em nível clínico e orientação populacional.

Com relação a COVID-19, Silva et al. (2020) trouxe informações sobre a testagem para identificação do novo coronavírus que começou com base na experiência colaborativa, acumulada no diagnóstico de vírus respiratórios que já infectaram a humanidade anteriormente e foram diagnosticados por meio da reação em cadeia da polimerase em tempo real (RT-qPCR), temos como exemplo a epidemia da SARSCoV em 2003, assim foi definido e validado o processo para seu uso no rastreamento e confirmação diagnóstica do novo coronavírus utilizando amostras de secreções esse procedimento tornou-se o protocolo oficial da OMS. 
No âmbito da realização de testes para COVID-19 Albuquerque et al. (2020) destaca que a probabilidade para obtenção de um resultado positivo, pode variar com o tipo de amostra biológica, qualidade da coleta, sendo necessária a preparação na realização deste procedimento; existindo ainda uma variedade na dinâmica da carga viral que repercutem no acondicionamento e transporte das amostras. Além do risco elevado de contaminação para os profissionais que trabalham com a extração de amostra e o manuseio do material, destacando a importância da implementação de protocolos de biossegurança.

Segundo Magalhães (2020) os testes laboratoriais utilizados para detectar o SARSCoV-2 são: Testes de biologia molecular RT-PCR, que detecta RNA viral e que é o mais indicado para a confirmação da COVID-19; Testes de antígeno que detectam proteínas, tais como proteínas da superfície do vírus e apresentam sensibilidade menor que o teste de biologia molecular; Testes sorológicos que detectam anticorpos $(\lg \mathrm{A}, \lg \mathrm{G}, \lg \mathrm{M})$ produzidos como resposta do sistema imunológico do indivíduo à infecção pelo vírus e não são recomendados para diagnóstico de novos casos.

\subsection{TESTES DE BIOLOGIA MOLECULAR}

As análises de Vieira; Emery e Andriolo (2020) e as de Silva; Silva; Guarines et al. (2020), corroboram sobre essa metodologia, baseada na reação em cadeia da polimerase com transcrição reversa com reação de amplificação em tempo real (RTPCR). Essa técnica é considerada o teste padrão ouro para identificação da COVID19 pela sua sensibilidade e especificidade. O RT-PCR mostra-se mais eficiente do que o teste sorológico, por identificar casos positivos na fase inicial da doença, ainda durante o período de incubação ou sem a presença dos sintomas. Essa técnica está baseada na identificação do RNA viral. Os genes indicados para a identificação incluem N, E, S e RDRP; segundo o protocolo recomendado pela Organização Panamericana da Saúde (OPAS/OMS) e que tem sido adotado como padrão pela maioria dos países, a confirmação laboratorial dependia da detecção de dois marcadores genéticos, mas atualmente devido a elevada taxa de circulação do vírus e também a escassez de reagentes pode ser utilizada a identificação de apenas um marcador 
genético. Por ser o gene $\mathrm{E}$ o que tem maior sensibilidade, o Ministério de saúde do Brasil recomenda que ele seja o alvo.

Xavier et al. (2020) ressalta a indicação feita pelo Ministério da Saúde do Brasil para que a técnica de RT-PCR seja realizada entre o terceiro e o nono dia após o início dos sintomas, pois, nessa fase, é possível encontrar maior carga viral. Entretanto, a coleta de amostras pode ser aceitável se realizada até o décimo dia, no entanto, também nos informa que a partir do sétimo dia a positividade do teste começa a cair. Por ter uma identificação no começo da infecção o teste de biologia molecular é o ideal para indicar quem deve permanecer em isolamento e evitar a disseminação do vírus.

\subsection{TESTE DE DETECÇÃO DE ANTÍGENO}

Durante a pandemia foram desenvolvidos vários tipos de testes, mas nem todos são adotados pelas instituições de saúde para diagnosticar novos casos. Sobre os testes de detecção de antígeno do SARS-CoV-2, Magalhães (2020) e Oliveira (2020) ressaltam a sua metodologia de identificação, que é realizada por meio da detecção de proteínas virais em amostras coletadas no trato respiratório superior de pacientes com sintomas de infecção pelo novo coronavírus, estes testes não são usados como padrão para diagnóstico de COVID-19 porque tem sensibilidade menor do que os métodos de testagem da biologia molecular, com variação de sua carga viral. Assim, na fase inicial da infecção, a probabilidade de identificação do RNA viral por RT-PCR tem maior possibilidade de sucesso do que a detecção da presença de uma proteína do SARS-CoV-2. Devido às fracas performances destes testes, nos casos de carga viral baixa, estes não são recomendados pelas autoridades de saúde para uso clínico no quadro do COVID-19, fato que a Organização Mundial de Saúde (OMS) ressaltou na sua comunicação de 8 de abril de 2020, levando em consideração a sua baixa sensibilidade.

\subsection{TESTE SOROLÓGICO}

Os testes sorológicos apesar de não serem utilizados como padrão para diagnósticos de COVID-19, se caracterizam como métodos mais simples, De Sousa et al. (2020) 
que estes visam detectar anticorpos específicos produzidos pelo sistema imunológico do corpo humano contra o vírus SARS-CoV-2 ou detectar antígeno do novo coronavírus. Nesse caso, o exame é realizado a partir da amostra de sangue do paciente, esse material pode ser processado em laboratório para a extração de soro, podendo obter uma maior eficácia ou ser usado em forma natural. A faixa ideal recomendada para que os testes adquiriram maior sensibilidade, deve ser pelo menos, 10 dias após o início dos sintomas, justificada no fato de que produção de anticorpos do organismo só ocorre depois de um período mínimo após a exposição ao vírus, entretanto esta resposta imune pode variar de acordo com o indivíduo, principalmente em pacientes imunossuprimidos.

De acordo com as informações trazidas por Vieira, Emery e Andriolo (2020) a necessidade da testagem em um grande número de pessoas, sobrecarregou os laboratórios que não conseguiram disponibilizar testes moleculares para todos, no objetivo de suprir essa necessidade, as empresas produtoras de reagentes para diagnósticos laboratoriais começaram a desenvolver os testes sorológicos. Existem vários testes deste tipo no mercado liberados pela ANVISA, porém a OMS recomenda o seu uso apenas para fins epidemiológicos.

Em nota técnica da FIOCRUZ, Pavão et al. (2020) discorre sobre o diagnóstico laboratorial da COVID-19, a qual nos informa sobre os testes imunológicos ou sorológicos, que podem ser realizados por meio de duas técnicas diferentes: ELISA e ensaios imunocromatográficos. Esses dois processos são realizados com amostra de sangue do paciente e visam identificar anticorpos (IGM, IGG) produzidos no sistema imunológico do indivíduo infectado pelo novo coronavírus. Como já foi comprovado em estudos, os indivíduos infectados demoram em média de 7 a 11 dias para produzirem anticorpos, mesmo que algumas pessoas possam desenvolver anticorpos mais cedo. Indicando que, diferentemente dos testes moleculares, estes não são adequados para identificar quem deve ser isolado para evitar a propagação da doença, pois quando for realizado o teste, o paciente já teria carregado o vírus por muitos dias. 
Os exames sorológicos também são conhecidos como testes imunológicos por se basearem na resposta imune do paciente. Dias et al. (2020) conclui que esse equipamento ainda precisa de melhorias para ter sua sensibilidade aumentada e gerar resultados mais confiáveis no uso do diagnóstico laboratorial. Várias empresas produzem testes baseados em antígenos distintos, cada um com desempenho diferente, podendo apresentar variação de probabilidade de falsos-negativos sendo necessário submeter os novos testes a ensaios que forneçam um parâmetro para diagnóstico.

\section{CONCLUSÃO}

Conclui-se que os laboratórios desempenham uma função crucial no combate ao novo coronavírus. E mesmo com todas as limitações que esse segmento da área de saúde encontra rotineiramente, em relação à atenção aos profissionais da saúde, muitas vezes desvalorizados, precisam enfrentar os riscos da contaminação e a falta de recursos, para acompanharem da melhor maneira possível a demanda de testagem, nos diagnósticos e produção de resultados frente à pandemia.

Os testes laboratoriais têm função importantíssima no cenário de enfrentamento da pandemia do novo coronavírus, são responsáveis pelo diagnóstico dos pacientes contaminados com SARS-CoV-2, auxiliam na formulação de políticas públicas de saúde e de segurança, produzem dados que serão usados para a retomada das atividades econômicas e no relaxamento do isolamento social. O combate à COVID19 revelou as fragilidades nos sistemas de saúde, que por outro lado incentivou à realização de pesquisas que poderão ser utilizadas para o combate de patologias futuras.

Ficou claro que o sistema de saúde do Brasil não está preparado para combater uma ameaça como esta que nos atingiu, mostrando a necessidade de investimento na criação de mais laboratórios, adquirir tecnologias avançadas, no treinamento e capacitação de profissionais para atuarem frente ao cenários e futuros surtos emergentes na saúde, devendo portanto incentivar maiores pesquisas para que no 
futuro não sejamos impactados como o SARS-CoV-2 revelou nos seus resultados desastrosos referentes à morbimortalidade mundial.

\section{REFERÊNCIAS}

ALBUQUERQUE, Margarida et al. Pandemia SARS-CoV-2: A Perspetiva do Laboratório de Patologia Clínica do Hospital CUF Infante Santo E tudo o SARS-CoV2 mudo. Gazeta Médica, 2020.

DE SOUSA, Fabiana Cristina Belchior et al. Protocolos utilizados para diagnóstico de COVID-19. REVISTA DA FAESF, v. 4, 2020.

DIAS, Viviane Maria de Carvalho Hessel et al. Testes Sorológicos para COVID-19: Interpretação e Aplicações Práticas. Journal of Infection Control, v. 9, n. 2, 2020.

LIPPI, Giuseppe; PLEBANI, Mario. Resiliência dos laboratórios clínicos durante a pandemia de coronavírus 2019 (Covid-19). Jornal Brasileiro de Patologia e Medicina Laboratorial, v. 56, 2020.

LIPPI, Giuseppe; PLEBANI, Mario. The critical role of laboratory medicine during coronavirus disease 2019 (COVID-19) and other viral outbreaks. Clinical Chemistry and Laboratory Medicine (CCLM), v. 1, n. ahead-of-print, 2020.

Loeffelholz MJ, Tang YW. Laboratory diagnosis of emerging human coronavirus infections - the state of the art. Emerg Microbes Infect. 2020;9(1):747-756. doi:10.1080/22221751.2020.1745095.

MAGALHÃES, Sónia. SARS-CoV-2: Diagnóstico Laboratorial. Acta Farmacêutica Portuguesa, v. 9, n. 1, p. 32-37, 2020.

OLIVEIRA, Jorge Nunes. O Laboratório de Análises Clínicas na Pandemia COVID19. Revista Portuguesa De Farmacoterapia, v. 12, n. 1-2, p. 56-60, 2020.

PAVÃO, Ana Luiza et al. Considerações sobre o diagnóstico laboratorial da Covid-19 no Brasil. Observatório Covid-19 Fiocruz, 2020. Nota técnica. 20p. 
SILVA, Renan Gonçalves Leonel da et al. A participação da universidade na produção de testes diagnósticos moleculares do novo coronavírus no Brasil: resposta aos desafios sanitários. Cadernos de Saúde Pública, v. 36, p. e00115520, 2020.

Silva SJRD, Silva C, Guarines K, et al. Clinical and Laboratory Diagnosis of SARSCoV-2, the Virus Causing COVID-19 [published online ahead of print, 2020 Aug 4]. ACS Infect Dis. 2020;10.1021/acsinfecdis.0c00274. doi:10.1021/acsinfecdis.0c00274

VIEIRA, Luisane Maria Falci; EMERY, Eduardo; ANDRIOLO, Adagmar. COVID-19Diagnóstico Laboratorial para Clínicos, 2020.

XAVIER, Analucia R. et al . COVID-19: manifestações clínicas e laboratoriais na infecção pelo novo coronavírus. J. Bras. Patol. Med. Lab., Rio de Janeiro , v. 56, e3232020, 2020 Available from

$<$ http://www.scielo.br/scielo.php?script=sci_arttext\&pid=S1676-

24442020000100302\&lng=en\&nrm=iso >. access on 13 Aug. 2020.

Enviado: Outubro, 2020.

Aprovado: Outubro, 2020. 